\title{
A conceptual framework for design of mobile governance in developing countries: the case of Bangladesh
}

\begin{abstract}
Mobile governance (m-governance), which is considered as an extension of electronic governance (egovernance), has enormous opportunity to flourish in the developing countries due to the rapid increase of mobile phone subscribers. There are also a number of challenges accompanying the opportunities for design and implementation of mobile governance in developing countries. In this paper a conceptual framework is proposed based on secondary research to justify the current mobile governance situation of developing countries, with Bangladesh being selected as the case study, by explaining the essential components of a mobile governance system and the surrounding environmental factors that have influence upon it.
\end{abstract}

Keywords- m-governance; mobile governance; egovernance; developing countries; Bangladesh; policy framework

\section{INTRODUCTION}

In this paper, section II define the term mobile governance, section III explains why mobile governance is a better choice. Section IV explains the overall mobile governance situation in developing countries. The frameworks and models related to the proposed conceptual framework are explained in section $\mathrm{V}$, with a comparison table. In section VI the approach of the research is explained. The different components of the proposed conceptual framework are discussed in section VII. In section VIII the conceptual framework is explained in detail, set against the current scenario of Bangladesh. Finally, a conclusion and future work are described in section IX.

\section{DeFInIG MobILE GOVERNANCE AND RELATIONSHIPS}

The term "government" refers as an organization that has the authority to construct and enforce laws for a certain country or territory. E-government is used to streamline or improve the process of government by using electronic technology. E-Government is a narrower topic providing online services to the citizens. E-Governance is a wider discipline that defines and assesses the impacts of technologies on the practices and the administration of governments and the relationships between public servants and wider society, such as dealing with elected bodies, not-for-profit organizations, NGOs or private sector corporate entities ([1][2]. As m-government is the extension of e-government and m-governance is the extension of e-governance [3], it could be concluded that m-government deals with a narrower discipline than $\mathrm{m}$-governance.

The strategy and implementation, using all kinds of wireless and mobile technology services, devices and their applications, to improve the mechanisms of delivery of public information and services to the citizens, business and government departments are referred to as m-governance [4][5].

\section{Why MOBILE GOVERNANCE ?}

Enhanced use of mobile phones and mobile internet use has provided a new platform for the users to interact with different mobile and internet services through their mobile phones [3]. These offer an individual and organizations the possibility to choose to use a wide range of activities anytime, anywhere using their mobile devices. On the other hand the improvements in the area of e-business and m-business offer governments the option to offer their services to the citizens and other public or private organizations effectively and efficiently by creating a new direction for e-government [6]. This allows online public services to be accessed [7] beyond the office premises and standard office hours [4]. The arguments in favour of the adoption of $\mathrm{m}$ government services are wider reach, always on the users person, always on, more personalization for targeting users, costeffective, better management, faster information flow, increased democracy, solution to the digital divide, better the lives of disabled etc. [8]. As a result, there are obvious reasons to extend e-governance to m-governance.

\section{Mobile Governance In Developing Countries}

Developed countries are already benefitting from mobile governance with the use of existing e-governance infrastructures. The mobile government systems allow citizens to access the government services more conveniently and reliably by opening a new channel. The systems also provide more localized services with the help of Smartphone and their functionality to use GPS [9].

Mobile or wireless networks seem a better choice for developing countries as the number of personal computers and fixed phone lines is very poor compared with possible access by mobile phones. As a result short message service (SMS), interactive voice response (IVR) or mobile internet could be an alternative means of connecting to the network to access the electronic services. It also may allow the governments of developing countries to reduce the need for heavy infrastructures that are required for the wired networks, thereby saving cost and time. The delivery of information is a key responsibility of government to make their citizens aware about what is happening around them, especially in the case of a critical situation when they need to make some decision. Mobile networks could provide the means for a critical channel for governments to provide timely information which proves the accountability of the government towards the democracy of the country [10].

Developing countries like Philippines, Chad, Burkina Faso, Honduras, Nigeria, South Africa, Saudi Arabia, Mongolia, Indonesia, Mexico, China, India, Turkey and Jordan are among the countries which have already implemented m-governance or are more likely to implement it due to rapid penetration of mobile subscribers [11][12][13].

Ghyasi and Kushchu [10] suggest that the government of developing countries can implement m-governance in three stages: in the first stage the governments should develop an 
application so that they can send text messages to the people at the time of an emergency;in the second stage the application should be in such a form that the people can communicate with govern

ment services in a more interactive way, in the third stage the application of mobile governance should be developed in such a way that it provides the full functionality of government services.

Like other developing countries the government of Bangladesh has already initiated an m-government process which is one of the government's 2000 Millennium Development Goals (MDGs). Especially the Ministry of Education, the Ministry of Agriculture, the Ministry of Communication and the Ministry of Health have their own processes to interact with the people with the help of the mobile operators [14].

\section{RELATED FRAMEWORKS AND MODELS}

There is considerable research into the development of different frameworks and models related to mobile/electronic governance/government systems.We have selected 18 different models and frameworks related to mobile governance/government to compare the suitability of the proposed conceptual framework. The selected models and frameworks address the problem of mobile governance/government from similar and largely complementary angles, and this gives rise to an opportunity for a holistic model, which we are attempting to address in this paper. Comparisons of selected models and frameworks with 16 key issues they addressed are presented in Table 1.

All the model/frameworks presented in Table 1 have addressed technological issues and most of them are contextualized on developing countries where technological issues are considered in a broad sense by including any hardware, software or technology related to ICT or mobile telephony. The model/frameworks developed by Azad [14], Al-Hadidi [15], Awotwi, Ojo and Janowski [16], Al-Masaeed [17], and Henning, Janowski and Estevez [18], have addressed a significant number of key issues.

Al-Hadidi [15] proposed an m-Government adoption model for Oman which explains different influences on adoption and successful implementation, but does not address other issues such as digital divide, finance \& payment, public and private partnership, or governing/business process. Awotwi, Ojo and Janowski [16] proposed a conceptual framework for mobile governance strategies for development (MGOV4D) to support mobile ICT for development (MICT4D), but do not address the issues related to economic, security and privacy, finance and payment, organizational and management, public and private partnership etc. Azad [14] suggested a conceptual framework to enable an m-governance service platform, influence development in socio-economic contexts, facilitate business environments (in ICT) and keep positive/negative environmental impact through public private partnership (PPP) in Bangladesh, but has not addressed other issues such as digital divide, finance and payment, legislative and policy etc. Al-Masaeed [17] explains mgovernment $\mathrm{G} 2 \mathrm{C}$ success factors model by covering most of the key issues, but has not addressed socio-cultural and payment issues. Henning, Janowski and Estevez [18] designed a Conceptual framework for mobile governance for sustainable
TABLE I. COMPARISON OF SELECTED MODELS AND FRAMEWORKS

\begin{tabular}{|c|c|c|c|c|c|c|c|c|c|c|c|c|c|c|c|c|}
\hline Developed By & 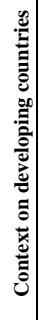 & 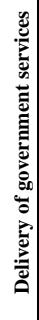 & 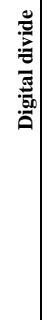 & 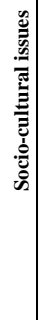 & 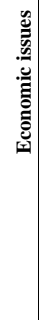 & 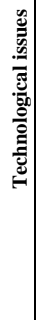 & 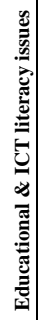 & 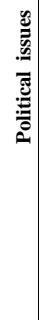 & 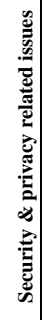 & 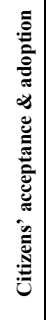 & 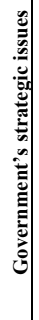 & 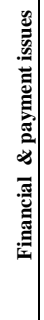 & 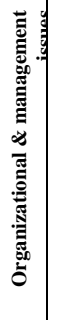 & 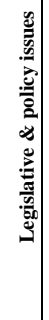 & 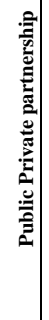 & 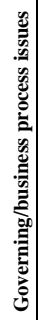 \\
\hline $\begin{array}{c}\text { Sundar and } \\
\text { Garg [20] }\end{array}$ & $\checkmark$ & $\sqrt{ }$ & & & & $\checkmark$ & & & & & & & & & & $\sqrt{ }$ \\
\hline Narayan [21] & $\sqrt{ }$ & $\sqrt{ }$ & $\sqrt{ }$ & & & $\sqrt{ }$ & $\sqrt{ }$ & & & $\sqrt{ }$ & & & & & & \\
\hline $\begin{array}{c}\text { Amailef and Lu } \\
{[22]}\end{array}$ & & $\sqrt{ }$ & & & & $\checkmark$ & & $\sqrt{ }$ & & & $\sqrt{ }$ & & $\sqrt{ }$ & & & $\sqrt{ }$ \\
\hline $\begin{array}{c}\text { Fasanghari and } \\
\text { Samimi [23] }\end{array}$ & $\sqrt{ }$ & $\sqrt{ }$ & & & & & & & & & & & & & & $\sqrt{ }$ \\
\hline $\begin{array}{c}\text { Hassan, Jaber } \\
\text { and Hamdan } \\
{[2]}\end{array}$ & & $\sqrt{ }$ & & & & $\checkmark$ & $\checkmark$ & & & $\sqrt{ }$ & & & & & & \\
\hline $\begin{array}{l}\text { Kiki, Lawrence } \\
\text { and Steele [24] }\end{array}$ & & & & $\sqrt{ }$ & & $\sqrt{ }$ & & $\sqrt{ }$ & & & $\sqrt{ }$ & & $\checkmark$ & & & $\sqrt{ }$ \\
\hline Al-Hadidi [16] & & & & $\sqrt{ }$ & $\sqrt{ }$ & $\sqrt{ }$ & $\sqrt{ }$ & $\sqrt{ }$ & $\sqrt{ }$ & $\sqrt{ }$ & $\sqrt{ }$ & & $\sqrt{ }$ & $\sqrt{ }$ & & \\
\hline $\begin{array}{l}\text { Alijerban and } \\
\text { Saghafi [25] }\end{array}$ & & $\sqrt{ }$ & & & & $\sqrt{ }$ & & $\sqrt{ }$ & & & & $\sqrt{ }$ & & $\sqrt{ }$ & & $\sqrt{ }$ \\
\hline $\begin{array}{c}\text { Awotwi, Ojo } \\
\text { and Janowski } \\
{[17]}\end{array}$ & $\checkmark$ & $\checkmark$ & $\sqrt{ }$ & $\sqrt{ }$ & & $\checkmark$ & $\sqrt{ }$ & $\sqrt{ }$ & & $\checkmark$ & $\sqrt{ }$ & & & $\sqrt{ }$ & & $\sqrt{ }$ \\
\hline Azad [15] & $\sqrt{ }$ & $\sqrt{ }$ & & $\sqrt{ }$ & $\sqrt{ }$ & $\sqrt{ }$ & $\sqrt{ }$ & $\sqrt{ }$ & $\sqrt{1}$ & $\sqrt{ }$ & $\sqrt{ }$ & & $\sqrt{ }$ & & $\sqrt{ }$ & \\
\hline Maranny [26] & & $\sqrt{ }$ & & & & $\sqrt{ }$ & & & $\sqrt{ }$ & $\sqrt{ }$ & & & $\sqrt{ }$ & $\sqrt{ }$ & & \\
\hline $\begin{array}{c}\text { Abdelghaffar } \\
\text { and Magdy [27] }\end{array}$ & $\sqrt{ }$ & & & $\sqrt{ }$ & & $\checkmark$ & & & $\checkmark$ & $\checkmark$ & & & & & & \\
\hline Duncombe [28] & $\sqrt{ }$ & & & & $\sqrt{ }$ & $\sqrt{ }$ & & $\sqrt{ }$ & & $\sqrt{ }$ & & & & & & $\sqrt{ }$ \\
\hline $\begin{array}{c}\text { Al-Masaeed } \\
{[18]}\end{array}$ & $\checkmark$ & $\sqrt{ }$ & $\sqrt{ }$ & & $\sqrt{ }$ & $\checkmark$ & $\sqrt{ }$ & $\sqrt{ }$ & $\sqrt{ }$ & $\sqrt{ }$ & $\sqrt{ }$ & & $\sqrt{ }$ & $\sqrt{ }$ & $\sqrt{ }$ & $\sqrt{ }$ \\
\hline $\begin{array}{c}\text { Al-Sakran, } \\
\text { Kharma and } \\
\text { Serguievskaia } \\
{[29]}\end{array}$ & & & & & & $\sqrt{ }$ & & & & & & & & & & \\
\hline $\begin{array}{c}\text { Ojo, Janowski } \\
\text { and Awotwi } \\
{[30]}\end{array}$ & & & & & & $\sqrt{ }$ & & & & $\sqrt{ }$ & & & & & & $\sqrt{ }$ \\
\hline $\begin{array}{c}\text { Henning, } \\
\text { Janowski and } \\
\text { Estevez [19] }\end{array}$ & & $\sqrt{ }$ & & $\sqrt{ }$ & $\sqrt{ }$ & $\sqrt{ }$ & $\sqrt{ }$ & $\sqrt{ }$ & $\sqrt{ }$ & $\sqrt{ }$ & $\sqrt{ }$ & & $\sqrt{ }$ & $\sqrt{ }$ & & \\
\hline $\mathrm{Yu}[31]$ & & $\sqrt{ }$ & & $\sqrt{ }$ & $\sqrt{ }$ & $\sqrt{ }$ & & & & & $\sqrt{ }$ & & $\sqrt{ }$ & & & \\
\hline $\begin{array}{c}\text { Proposed } \\
\text { conceptual } \\
\text { frame work }\end{array}$ & $\sqrt{ }$ & $\sqrt{ }$ & & $\sqrt{ }$ & $\sqrt{ }$ & $\checkmark$ & $\sqrt{ }$ & $\sqrt{ }$ & $\sqrt{ }$ & $\checkmark$ & $\sqrt{ }$ & $\sqrt{ }$ & & $\sqrt{ }$ & & $\sqrt{ }$ \\
\hline
\end{tabular}

development, but have not addressed issues such as digital divide, financial and payment, public-private partnership, governing/business process. Financial and payment related issues are found to be commonly missed out in the above mentioned model/frameworks. The rest of the selected model/frameworks addressed less than $50 \%$ of key issues. However, the proposed conceptual framework is designed to address most of the issues.

\section{RESEARCH APPROACH}

The research conducted in this paper is based on a literature review of secondary data. The conceptual framework derived from the literature review map, which was initially designed to map the scope of the literature related to mobile governance of developing countries. The literature research strategy started from a broad view of mobile governance, then it was iteratively refined in light of other existing frameworks and models, leading to a final version of the proposed conceptual framework, which will be explained in next section. Bangladesh was selected as the case study, to scrutinize the current mobile governance scenario in the light of the literature related to mobile/electronic governance/government in Bangladesh, by 
using the conceptual framework. A visual representation of the research approach is given in figure 1.

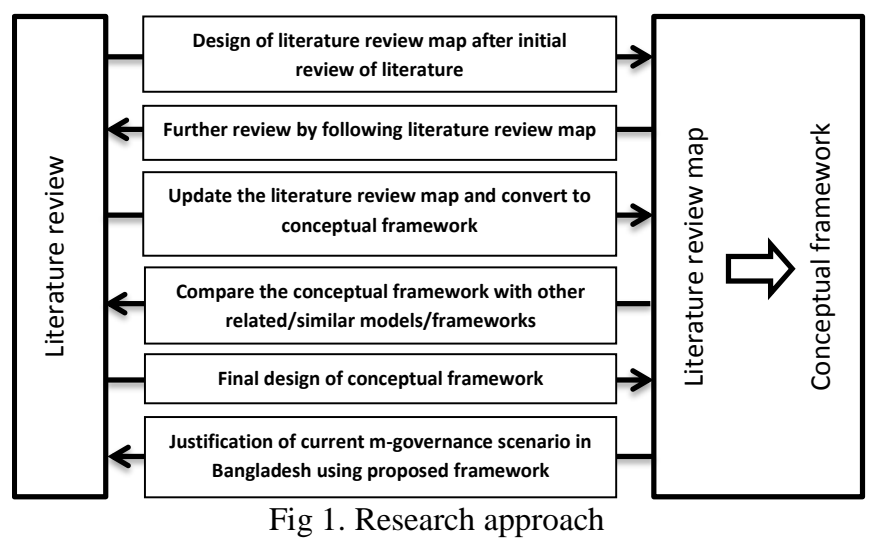

\section{PROPOSED CONCEPTUAL FRAMEWORK}

The proposed framework explains the obligatory components of mobile governance, influences of different environmental factors, and relations of mobile governance with existing electronic governance systems. The framework enables the users (of the framework) to examine and clarify the current readiness condition of mobile governance within a country, and recommend any further development towards the design of mobile governance. The tool could be useful for both the academic and non-academic community for research and commercial purposes.

To enhance the visual representativeness of the model, the conceptual framework has been developed in the shape of house, and its surrounding environment, building on a foundation of existing electronic governance. Like the residents of the house the users of the mobile governance system will feel more secure and comfortable because of those strong foundations.

The framework was developed around five main components with their subcomponents, which are shown in figure 2. They are:

a) Foundation: It is the base of the system on which the system will be built that consists of i) Data repositories/ data management for electronic/mobile governance; ii) Business/governance processes and iii) Existing electronic governance systems.

b) Pillars: They are used to keep the mobile governance system up and running efficiently, effectively and smoothly. They are i) Communication network infrastructure; ii) Citizens' awareness, acceptance and adoption; iii) Financial regulations related to mobile/electronic governance; iv) Online/mobile payments systems; v) Legislation related to electronic/mobile governance and vi) Government's strategies on electronic/mobile governance.

c) Roof: It protects the mobile governance system and its users from any unauthorized and unwanted access. The roof consists of i) Auditing and Monitoring; iii) Security and Privacy.

d) Entrances (points of entry): The users can access to services of the mobile governance system using three different ways. They are i) Access via short message service (SMS); ii) Access via mobile internet and iii) Access via Interactive Voice Response (IVR). e) Surrounding environmental factors: The mobile governance system and the user experience are influenced by different surrounding influential factors. They are i) Economic factors; ii) Political factors; iii) Media factors; iv) Legislative and policy factors; v) Socio-cultural factors; vi) Technological factors, vii) Educational factors and viii) Other related factors.

The details of conceptual framework will be discussed in next section in case of current mobile governance scenario of Bangladesh.

\section{CONCEPTUAL FRAMEWORK IN BANGLADESH PERSPECTIVE}

In this section, all components of the proposed conceptual framework will be explained in accordance with the current situation of Bangladesh. This will allow the stakeholders of the mobile governance in Bangladesh to scrutinize the readiness of different components of proposed framework as indicated in section VI.

\section{a) Foundation}

i) Data repositories/ data management for e/m-governance: As both e- and m-governance systems may use the same types of data, it is possible for the two to use the same data repositories In Bangladesh the database used for national e-content repository [31] could also be used for mobile governance systems as well.

ii) Business/Governance Processes: Business and governance processes allow the e/m-governance systems to perform according to the needs of the officials and the users. Most of the time it is possible to follow the same business and governance processes for both cases. Alam [32] suggested that Business/governance processes in Bangladesh should be automated in such a way that the user can fill the forms and make necessary amendments without visiting government offices. This allows the users to have the ability to access and disseminate information in an effective and efficient way.

iii) Existing E-governance platforms: The existing egovernance platform allows the m-governance system to sit on it to access the existing information and style. This also may reduce the cost and duration of the project. The diverse functionalities and work abilities of the existing platforms are important as they could be used for m-governance systems in appropriate and efficient ways which is equally true in the case of Bangladesh [33]. In Bangladesh the e-governance is well established and allows the people in remote areas to access data from national econtent repository [31].

\section{b) Pillars}

i) Communication network infrastructure: Strong mobile network infrastructure ensuring high quality coverage in mobile services (including GPS), are essential to provide mobile government with localized services [34]. Research shows that Bangladesh is well covered with mobile and data network [35] and GPS is in its initial stage of implementation [36].

ii) Citizen awareness, acceptance and adoption: The success of m-governance depends on engagement of both government and citizens. There is always a hidden challenge to make the technology acceptable to the citizens [37]. According to Azad [14] sometimes due to financial reasons, the users cannot afford the technology, although there is a high demand. However, research shows the users in Bangladesh are in favor of acceptance and adoption of these kinds of m-technologies [38].

iii) Financial regulations related to e/m-governance: The country should have specific financial rules and regulations in 
place related to e/m-governance to ensure user confidence and trust in use of the system. This is the central financial regulatory body of the country, which is supposed to draft the financial regulations related to $\mathrm{e} / \mathrm{m}$-governance, mainly related to electronic and mobile payments. The government of Bangladesh introduced mobile finance services (MFS) with the help of Bangladesh Bank (central bank of Bangladesh) and Bangladesh Telecommunication Regulatory Commission (BTRC,) which allow the users of the services to use different payment systems, which will support the implementation of mobile governance [35].

iv) Online/mobile payment system: Without having effective and efficient online/mobile payment system in place the e/m-government services could be inconvenient. "bKash" is widely used mobile payment service in Bangladesh [39]. However, other types of the electronic payment systems are not widely reachable by a significant proportion of people including the people living in remote areas [40].

v) Legislation related to e/m-governance: Though legislative factors are considered as an important factor in implementation of e/m-governance, it is also important to have specific legislation related to e/m-governance. The lack of legislation may slow down the implementation of m-governance [41]. According to Azad [14] in Bangladesh, though a number of regulations are in favor of $\mathrm{m}$-governance, some of them may discourage the mobile phone operators from providing the relevant services.

vi) Government strategies on e/m-governance: The strategies of the government on a particular new technology like mgovernance not only indicate government plans about the technology, but also indicate whether the government is interested in implementing the technology and allowing citizens to access and use the technology. Research shows that the government's strategies are in favor of e/m-governance in Bangladesh [35][42].

\section{c) Roof}

i) Auditing and Monitoring: The government of the country needs to facilitate the m-governance system with sufficient auditing and monitoring, with the help of some regulatory bodies or specialized organization to make the system safe and smooth for the users, which will also increase the confidence and trust of the users in using it [43][44]. However, Bangladesh is in its initial planning stage for the implementation of auditing and monitoring for e/m-governance [40][45].

ii) Security and Privacy: Security and privacy of data plays an important role to secure the e/m-government services as there is a high possibility that intruders will try to access personal or government confidential information. Security and privacy are considered as one of the most important issues towards the implementation of e/m-governance from both the citizens and government perspective [3][9][37]. Research shows the users of $\mathrm{m}$-technologies of Bangladesh are concerned about security and privacy [38][46].

\section{d) Entrances}

i) Access via SMS: Access to mobile governance services via short message services (SMS) means that the accessibility is universal irrespective of mobile handsets. In Bangladesh the students are allowed to enter themselves in university admission process by applying via SMS [14]. SMS is also used to warn people of natural disasters like cyclones and floods [8].

ii) Access via Mobile Internet: The m-governance services could be accessed in a very flexible way using a combination of
Global Positioning System (GPS) and mobile internet, as these are able provide more localized and customized services. In Bangladesh most of areas are covered with $2 \mathrm{G}$ data network and some of the areas with $3 \mathrm{G}$ [35] and GPS is being used is few cases [37].

iii) Access via IVR: Interactive Voice Response (IVR) is another medium to access m-governance or existing e-governance services, which help to provide a 24/7 service [47]. In Bangladesh m-governance services are provided to farmers to help with their cultivation. The mobile phone operators, with the help of

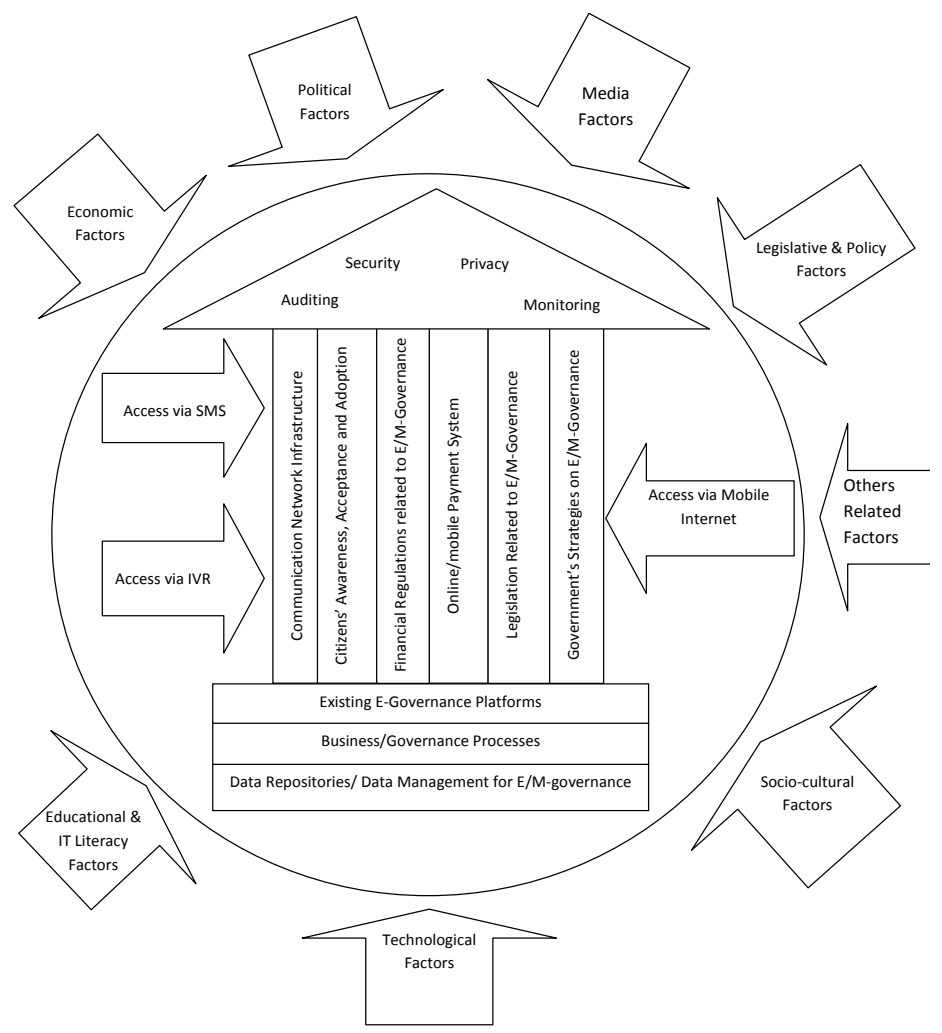

Fig 2. Proposed conceptual framework for mobile governance

government data repository, prefer to use IVR to interact with the farmers [14].

\section{e) Surrounding environmental factors}

i) Economic factors: Economic factors are among the crucial factors to implement e/m-governance in developing countries, as these factors decide whether the government of the country can afford such a system, and the users of the systems can afford to buy terminals like computers, mobile phones or tablets to use the services. In developing countries like Bangladesh, although there is a growing demand to use ICT products like mobile phones, the demands may not be enough of a trigger to buy the products due to the lack of affordability. The ICT products may also be considered as luxury products by some [14].

ii) Political Factors: Political factors are among the key factors for the implementation of e/m-governance [48] as all the decisions regarding implementation are meant to come from the political leaders. Bhuiyan [49] suggested that e-governance systems may reduce corruption and poverty in Bangladesh if there is a political will. Political unrest could also have an impact 
on the implementation of e/m-governance [50] and it is important to have political stability for a successful implementation [51].

iii) Media Factors: There are always critical influences of different media like newspaper, radio, television, social media [52] with regard to the national politics of a country. Therefore it is obvious that there is also a great impact of these media in the implementation and adoption of the m/e-governance. Nowadays, social media plays a strong role in delivering political messages and views to thousands of users with a single click, which can also be personalized. Television and radio talks allow citizens to interact with their political leaders directly to express their views. Research shows that the users of social media like Facebook is increasing rapidly in Bangladesh due to the implementation of $3 \mathrm{G}$ data network [35].

iv) Legislative and Policy Factors: Legislative and policy factors indicate that whether the country is ready for the implementation of e/m-governance, which is also important for the users of the systems for their comfort and confidence [50]. Overall the legislation and policies of Bangladesh are in favor of the implementation of e/m-governance [35].

v) Socio-Cultural Factors: In developing countries social and cultural factors play a significant role in adoption and implementation of new technologies like e/m-governance. People of such countries consider themselves superior to other members of society by having new technologies in their hands. Socioculturally the people of Bangladesh are more open and keen to accept new technologies irrespective of their religious background and financial ability [38].

vi) Technological Factors: The technological factors work as prerequisites for ensuring the readiness for the implementation of $\mathrm{e} / \mathrm{m}$-governance. The government of Bangladesh is taking a number of initiatives, such as creating hi-tech parks to provide sustainable business environments for the technology related industries and exempting income tax for all software and ICT Service companies until 2015 [36][42].

vii) Educational and ICT literacy Factors: Strong technical knowledge, skills and expertise of the project leaders and team members, who deal with newer technology like e/m-governance, are in short supply and this may lead to project failures [53]. The lack of education and the skills of the users (citizens) may also lead to failure of e/m-governance projects, as significant numbers of the users may not able to use the system [50]. Alam [32] suggested to train government officials regularly to implement the systems successfully in case of Bangladesh.

viii) Other Related Factors: The other related factors deals with the factors which may not be categorized under any of above factors. These factors may not be as influential as the others but could still have a high impact in implementation and adoption of e/m-governance. For instance any treaty with the neighboring countries, public-private partnership, digital divide, organizational and management issues may influence the design of the system. According to Azad [14] the public-private partnership issue is a key to implement a mobile governance system in Bangladesh.

From the above discussion it is clear that the situation in Bangladesh is quite favourable for the development of mobile governance. However, more focus should be given to the issues related to security, privacy, auditing and monitoring.

\section{CONCLUSION AND FUTURE WORK}

Developing countries are in the initial stages of implementing mobile governance. It is hoped that the proposed framework will help stakeholders to understand the design process, and to identify gaps within existing approaches during the design phase. The proposed conceptual framework is more appropriate for developing countries, as most of the literature reviewed considers the mobile/electronic government/governance system of developing countries, due to the scope of the project. However, there is no evidence that it will not work for the developed countries. There are further opportunities for research to investigate whether the framework is appropriate for the developed countries.

In future the conceptual framework could be justified against the design of some mobile governance projects from developing countries. They could be taken as a case study and used to identify whether the proposed framework is appropriate in designing different implementations of e/m-governance.

\section{REFERENCES}

[1] V. Godse and A. Garg, "From E-government to E-governance," in Proc. of 5th International Conference on E-governance, Hyderabad, India, Dec. 2007, pp.13-20

[2] M. Hassan, T. Jaberand Z. Hamdan, "Adaptive Mobile- Government Framework," in Proc. International Conference on Administrative Development: Towards Excellence in Public Sector Performance, Riyadh, Kingdom of Saudi Arabia, Nov. 2009, pp. 1-11,

[3] OECD, (2011). M-Government Mobile Technologies for Responsive Governments and Connected Societies [Online]. Available: http://www.itu.int/pub/D-STRGOV.M_GOV-2011

[4] DIT, (2012). Framework for Mobile Governance [Online] Available: http://deity.gov.in/sites/upload_files/dit/files/Framework_Mobile_Governance_171 2012.pdf

[5] S. Karunakaran, "Mobile Governance: The Kerala Experience and Insights for a Comprehensive Strategy," European Journal of ePractice, no. 12, pp. 1-12 · Mar. 2011.

[6] I. Kushchu. (2009). Introducing Mobile Government [Online]. Available: http://www.mgovernment.org/wp-content/uploads/2011/03/mgovintro.pdf

[7] J. Vincent and L. Harris, "Effective use of Mobile Communication in Egovernment -How do we reach the tipping point?," Information, Communication and Society, no. 11, vol. 3, . pp 395-413, 2008

[8] R. Rannu, S. Saksing and T. Mahlakõiv.(2011), Mobile Government: 2010 and Beyond (White Paper) [Online]. Available http://www.mobisolutions.com/files/mobile\%20government\%202010\%20and\%20 beyond\%20v100.pdf

[9] T. Zefferer. (2011) Mobile Government: E-Government for Mobile Societies Stocktaking of Current Trends and Initiatives [Online]. Available: http://www.asit.at/pdfs/technologiebeobachtung/mobile_government_1.0.pdf

[10] A. F. Ghyasiand I. Kushchu. (2004). m-Government: Cases of Developing Countries [Online] Available: http://www.mgovernment.org/resurces/mgovlab_afgik.pdf

[11] E. Lallana. (2008). mGovernment: Mobile/Wireless Applications in Government [Online]. Available: http://www.egov4dev.org/mgovernment/index.shtml

[12] G. Song and T. Cornford. "Mobile Government: Towards a Service Paradigm," In Proc. 2nd International Conference On E-Government, Pittsburgh, USA, 2006, pp. 208-218.

[13] PTI, (2015). Prime Minister Narendra Modi asks IT experts to innovate for ' $m$ Governance' $^{\prime}$ [Online]. Available: http://articles.economictimes.indiatimes.com/2015-0130/news/58625622_1_digital-india-prime-minister-narendra-modi-e-governance

[14] T. Azad, "The Emergence of Mobile-governance in Bangladesh, In What Extent, Mobile-governance Services are Facilitating Flexible \& Sustainable 'Government to Public' (G2P) Communication?”, MSc Thesis, Lund University, Lund, Sweden, 2011. 
[15] A. Al-Hadidi,“An Exploratory Study on Adoption and Diffusion of m-Government Services in the Sultanate of Oman", PhD Thesis, Cardiff University, Cardiff, United Kingdom, 2010.

[16] J. Awotwi, A. Ojo and T. Janowski, "Mobile Governance for Development Strategies for Migrant Head Porters in Ghana," in Proc. 5th International Conference on Theory and Practice of Electronic Governance, Cairo, Egypt, Dec. 2011 pp. $175-184$

[17] S. Al-Masaeed, "Towards A User-Centric Mobile Government in Jordan," PhD Thesis, Brunel University, London, United Kingdom, 2013

[18] F. Henning, T. Janowski and E. Estevez, (2014). Towards a Conceptual Framework for Mobile Governance for Sustainable Development (MGOV4SD): Reviewing the Literature and State of the Art in an Emerging Field [Online]. Available:

https://www.scss.tcd.ie/disciplines/information_systems/egpa/docs/2014/HenningJ anowskiEstevez.pdf

[19] D. K. Sundar and S. Garg, (2005). M-Governance: A Framework for Indian Urban Local Bodies [Online]. Available: http://www.grchina.com/mobility/lab/Archives/EuromGov2005/PDF/41_R359SK. pdf

[20] G. Narayan, "Addressing The Digital Divide: E-Governance and M-Governance in a Hub and Spoke Model ," The Electronic Journal on Information Systems in Developing Countries, no. 31, vol 1, pp 1-14, 2007.

[21] K. Amailef and J. Lu, "m-Government: A Framework of Mobile-based Emergency Response Systems," in Proc. 2008 3rd International Conference on Intelligent System and Knowledge Engineering, China, 2008, pp. 1398-1403.

[22] M. Fasanghari and H. Samimi,“A Novel Framework for M-Government Implementation," in Proc. 2009 International Conference on Future Computer and Communication, Kuala Lumpar, Malaysia, Apr. 2009, pp. 627-631.

[23] T. E. Kiki, E. Lawrence and R. Steele,"A Management Framework for Mobile Government Services," University of Technology, Sydney, 2009

[24] M. Alijerban and F. Saghafi, "M-government Maturity Model with Technological Approach," in Proc. 2010 4th International Conference on New Trends in Information Science and Service Science (NISS), Gyeongju, Korea,May. 2010, pp. 164-169

[25] E. A. Maranny.(2011).Stage Maturity Model of m-Government (SMM m-Gov) Improving e-Government performance by utilizing mGovernment features, [Online] Available: http://essay.utwente.nl/62691/1/EAMaranny_Thesis_SMM_m-Gov.pdf

[26] H. Abdelghaffar and Y. Magdy, "The Adoption of Mobile Government Services in Developing Countries: The Case of Egypt," International Journal of Information no. 2, vol 4, pp. 333-341, 2012

[27] R. Duncombe, (2012). Understanding Mobile Phone Impact on Livelihoods in Developing Countries: A New Research Framework [Online]. Available: http://www.sed.manchester.ac.uk/idpm/research/publications/wp/di/documents/di_ wp48.pdf

[28] H. O. Al-Sakran, Q. Kharma and I. Serguievskaia, "Agent Based Framework Architecture for Supporting Content Adaptation for Mobile Government," International Journal of Information Management (IJIM), no. 7, vol. 1, pp. 10-15, Jan. 2013

[29] A. Ojo,T. Janowski and J. Awotwi, "Enabling development through governance and mobile technology," Government Information Quarterly, no. 30, pp. 532-545, 2013

[30] C. C. Yu, "Developing Value-Centric Business Models for Mobile Government," in EGOV, M. Janssen et al. Ed. 2014, pp. 325-336,

[31] A. U. Zaman, (2011). Union Information \& Service Centre (UISC): ICT enabled one-stop service outlet in Bangladesh [Online] Available: http://community.telecentre.org/profiles/blogs/union-information-amp-servicecentre-uisc-ict-enabled-one-stop?xg_source=activity

[32] M. J. Alam, "E-Governance in Bangladesh: Present Problems and Possible Suggestions for Future Development," International Journal of Applied Information Systems (IJAIS), no. 4, vol. 8, pp 21-25, 2012.

[33] S. A. A. Rajon and S. A. Zaman,"Implementation of E-Governance: Only Way to Build a Corruption-Free Bangladesh," in Proc. 11th International Conference on Computer and Information Technology (ICCIT 2008), Khulna, Bangladesh, Dec. 2008, pp. 430-435
[34] J. E. Mtingwi,"Mobile Government Readiness in Africa: The Case of Malawi," Master's Thesis , University of Cape Town, South Africa, 2012

[35] B. A. Lucini and T. Hatt, (2014). Analysis Country overview: Bangladesh, Mobile for development impact [Online] Available: https://gsmaintelligence.com/research/?file=140820-bangladesh.pdf\&download

[36] P. De and M. Majumdar, (2014). Developing Cross-Border Production Networks between North Eastern Region of India, Bangladesh and Myanmar: A Preliminary Assessment, Research and Information System for Developing Countries [Online] Available: http://www.ris.org.in/images/RIS_images/pdf/Final\%20PrintCross\%20Border\%20Monograh-WEB.pdf

[37] A. T. Thunibat,N. A. M Zin and N. Sahari, "Mobile Government User Requirements Model", Journal of E-Governance, no. 34, pp. 104-111, 2011.

[38] M. S. Hossain And M. R. A. Khandanker, "Implementation Challenges of Mobile Commerce in Developing Countries- Bangladesh Perspective," in Proc. 14th International Conference on Computer and Infonnation Technology (ICCIT 2011), Dhaka, Bangladesh, Dec. 2011, pp. 399-404.

[39] K. Quadir, (2014). The Story of bKash, The Daily Star [Online], Available http://www.thedailystar.net/the-story-of-bkash-21235

[40] M. Mohiuddin, "Trend and Development of E-Banking: A Study on Bangladesh," IOSR Journal of Business and Management (IOSR-JBM), vol. 16, iss. 5, pp. 16-24, May. 2014

[41] CEG, (2014). Mobile Governance for Small Island Developing States - Strategy Knowledge Base, Center for Electronic Governance [Online], Available: http://www.cto.int/media/research/projects/Knowledge $\% 20$ Base $\% 20$ Deliverable $\%$ 20Report.pdf

[42] NBU, (2014). ICT Sector Study Bangladesh Bridging the Gap between Dutch and Bangladeshi ICT sectors, Netherlands Bangladesh Business Platform [Online]. Available: http://www.basis.org.bd/resource/ICT\%20Sector\%20Study\%20Bangladesh.pdf

[43] Y. Chen and P. Chu, Electronic Governance and Cross-Boundary Collaboration Innovation and Advancing Tools, Hershey : Information Science Reference, 2012

[44] M. T. Banday and M. M. Mattoo (2013). Social Media in e-Governance: A Study with Special Reference to India, Social Networking[Online]. Available: http://www.scirp.org/journal/sn

[45] A2I, ,(2007). e-Governance Horizon Scan Report An assessment of e-governance in Bangladesh, Access to Information (A2I) Programme [Online]. Available: http://elearning.bim.org.bd/uploads/376607804b682a3c14b1ea428e0f8e42.pdf

[46] M. S. Islam,"Mobile Banking: An Emerging Issue in Bangladesh," ASA University Review, vol. 7, no. 1, pp. 123-130, May. 2013

[47] F. Abdulfattah,"The effect of electronic customer relationship on custome satisfaction a study in web banking in Saudi Arabia," Doctoral thesis, University of Huddersfield, United Kingdom, 2012

[48] S. Al-Shafi, S., " Factors affecting e-government implementation and adoption in the State of Qatar", PhD thesis. Brunel University, London, United Kingdom, 2009

[49] S. H. Bhuiyan, "Modernizing Bangladesh public administration through egovernance: Benefits and challenges," Government Information Quarterly, vol. 28, pp. 54-65, 2011

[50] M. M. Rahman and S. A. A. Rajon, "An effective framework for implementing electronic governance in developing countries: Bangladesh perspective," International Journal of Computer and Information Technology (IJCIT), vol. 3 , iss. 1, pp. 20-29, 2012

[51] M. R. Hassan,. "E-Governance and E-Government in Bangladesh: Performance, Challenges and Remedies," Asian Journal of Applied Science and Engineering, vol. 2, no. 2,pp. 111-117, 2013

[52] M. J. Magro, "A Review of Social Media Use in E-Government," Open Acces. Administrative Sciences, vol 2, pp. 148-161, Apr. 2012

[53] R. Heeks, (2013) Most eGovernment-for-Development Projects Fail: How Can Risks be Reduced? [Online], Available:http://unpan1.un.org/intradoc/groups/public/documents/NISPAcee/UNP AN015488.pdf 